\title{
Effect of the sampling device on fat and protein variation in cow milk samples obtained for official milk recording
}

\author{
R. Fouz, ${ }^{*}$ E. Yus, $†$ M. L. Sanjuán, $†$ and F. J. Diéguez $\nmid \ddagger^{1}$ \\ *Africor Lugo, Ronda de Fingoi, 117, 27002, Spain \\ †Institute of Food Analysis and Research (Animal Health and Epidemiology Unit), and \\ $\ddagger$ Anatomy and Animal Production Department, Veterinary Faculty of Lugo, Santiago de Compostela University, Campus Universitario, 27002 \\ Lugo, Spain
}

\begin{abstract}
The paper was designed to assess the effect of the type of milk meter used by dairy farms for official milk testing to obtain individual milk samples for fat and protein determination. This study was performed in 2006 in Galicia, which is Spain's main dairy cattle region; data were collected from 2,149 Holstein cow farms enrolled for official milk recording. Findings indicate that the milk sampling system used has a substantial effect on the fat contents recorded for individual milk samples. Such variation could arise from poor functioning of the equipment, inadequate mixing of the milk portion from which the sample is obtained, or from the nonproportionality of the sample. Samples obtained from only one point in the milk line may not be representative of all the milk produced. The most significant differences are observed in the percentage of fat, whereas differences in percentage of protein are smaller. The sampling method used should, but does not always, provide a representative sample of the milk from a single milking.
\end{abstract}

Key words: milk recording, sampling, fat, protein

\section{INTRODUCTION}

The reliability of the results of analyzing raw milk samples is very important for most dairy farmers and for the milk industry itself. Monthly data obtained for each cow (such as milk yield, milk fat and protein content, and SCC) are used to calculate the genetic value of the animal and sometimes form the basis of management decisions in nutrition, mastitis control, and reproductive programs or in planning animal replacements.

Many factors are known to contribute to variations in milk fat and protein determinations (Coleman and Moss, 1989; Schutz et al., 1990; Neitz and Robertson, 1991; Bertrand, 1996). The physical structure of milk is

Received January 26, 2009.

Accepted June 22, 2009

${ }^{1}$ Corresponding author: franciscojavier.dieguez@usc.es complex and includes 3 aggregation states: an emulsion of butterfat globules in a water-based fluid; aggregates of casein proteins forming micelles; and a dissolution containing the remaining proteins (whey proteins), the carbohydrate lactose, and some of the mineral components of milk. This means the risk of not obtaining a representative sample is high unless the volume of milk from which the sample is taken is sufficiently well mixed (Quinn-Whelton et al., 2007). In effect, the concentration of fat in milk can vary from $2 \%$ at the outset of milking to $8 \%$ at the end. Accordingly, the use of systems that obtain percentage samples will ensure that all the milking fractions are represented (Whittemore, 1980).

Milk samples for official testing are essentially obtained using 3 types of milk meters: portable, volumetric, and those that undertake electronic determinations. When using a portable machine, a fixed portion of each milking fraction flowing through the meter is diverted into a sample cup; thus, this type of sample is representative.

Volumetric measurers are permanently installed in the milk line and consist of a glass jar into which all the milk from one milking is deposited. At the bottom of the jar, a valve allows samples to be collected. The milk is mixed by opening the valve with the vacuum on so that air bubbles through the milk for 3 to $5 \mathrm{~s}$ before the vacuum is turned off and milk drops into the collection bottle. However, this is insufficient for complete mixing and a second mixing time is recommended for every liter of milk in the measuring jar (Olson and Amick, 1985). Because fat globules under gravity move toward the top of the jar, mixing is essential and should be more intense the greater the volume of milk in the measuring jar (such as for high-producing cows; Ma and Barbano, 2000). Using this type of milk meter, the long mixing time required will cause delays in milking and destabilization of fat globules, with the consequent risk of lipolysis and its associated problems, such as rancid off-flavors (Deeth and Fitzgerald, 1978; ICAR, 2002).

Using an electronic meter, the milk from the entire milking passes through a device in which a valve opens 
when a certain quantity is reached (200 to $300 \mathrm{~g}$ ); this milk returns to the pipeline and the device refills. Each volume released is measured and used to measure milk yield per cow. A portion of the milk that passes through the device is deposited in a collection bottle from which the sample is taken at the end of the milking. The volume of milk transferred to this collection bottle varies according to the instrument model, as does the degree of proportionality. That is, some models collect a portion of each of the milking fractions, whereas others fill up with milk at the start or end of milking. Samples taken using these devices may not be representative in terms of fat contents for 2 reasons: first, because of a lack of proportionality in milk passage to the sample collection bottle, and second, because of gravitational displacement of fat globules to the top of the sample collection bottle with no system for prior mixing. The concentration of protein in milk is more stable than that of fat (Quinn-Whelton et al., 2007) and should not, in principle, be affected by the proportionality or mixing of the sample.

This study was designed to assess the effect of the type of milk meter used to obtain individual milk samples for fat and protein determination by dairy farms enrolled for official milk testing.

\section{MATERIALS AND METHODS}

\section{Area Description}

This study was performed in 2006 in Galicia, which is Spain's main dairy cattle region. In 2006, milk yield in Galicia amounted to around 35\% of the country's total milk production, corresponding to approximately $1.7 \%$ of the milk produced in the European Union.

\section{Sample Collection}

Data were collected from 2,149 Holstein cow farms enrolled for official milk recording. These data comprised mean milk production per lactation and milk protein and fat levels for each farm, including data for all cows ending lactation in 2006, estimated by the Fleischmann method from monthly test-day data (Wilmink and Ouweltjes, 1992). Each farm was classified according to the milk sampling method used and the number of lactations completed over the year.

Milk production data were assigned to 4 categories according to the quartiles of the variable mean milk production per cow, as farms showing mean milk yields of 7.155 or less, 7.156 to $8.085,8.086$ to 9.104 , and 9.105 or more $\mathrm{kg} /$ lactation. In turn, farms were also classified according to the quartiles of the total number of lactations recorded for animals in production, as those with 18 or fewer, 19 to 24,25 to 33 , and 34 or more lactations completed before the end of 2006 .

In total, 61,020 lactations were analyzed. Lactations were normalized to a maximum of $305 \mathrm{~d}$ with a minimum duration of $240 \mathrm{~d}$ to ensure at least 7 official milk tests per lactation.

\section{Fat and Protein Measurements}

Samples were collected in plastic $50-\mathrm{mL}$ containers to which a preservative, bronopol (2-brono-2-nitro-1,3propanediol) had been previously added. Mean values of fat and protein for each lactation were calculated from the results obtained in tests conducted monthly on each animal by infrared spectroscopy (Milko Scan, Foss, Hillerød, Denmark).

\section{Statistical Analysis}

All statistical tests were performed using SPSS 15.0 software (SPSS Inc., Chicago, IL). The effect of the type of sampling system on percentage of fat and protein was examined by ANOVA. To correct the sampling system effect on percentage fat and protein for the effects of mean milk production and number of lactations, we used multivariant 3-way ANOVA that let us evaluate potential biologically important interactions. It was checked that the data fulfilled assumptions of normality and homogeneity of variance by means of Kolmogorov-Smirnov and Shapiro-Wilks and Levene tests, respectively. The results of these tests allow acceptance of ANOVA as valid for the means of comparison by sampling system.

\section{RESULTS}

The systems used for milk sampling were electronic in $16.6 \%$ of the farms $(27.7 \%$ of lactations), portable in $62.2 \%$ of the farms ( $51 \%$ lactations), and volumetric devices in $21.2 \%$ of the farms (21.3\% lactations).

Box diagrams of fat and protein percentages for the different sampling systems are shown in Figures 1 and 2 , respectively. These indicated how, in the case of percentage of fat, the 2 central quartiles did not overlap for any of 3 types of sampling.

Mean milk fat contents by farm sampling system used are provided in Table 1. Differences among the fat contents for the different sampling systems were significant. Further, in multiple means comparisons, significant differences were also detected when each sampling system was compared with the remaining 2 systems.

In the multivariate analysis, it was observed that mean milk production was also able to explain part of 
Table 1. Milk fat contents by sampling system used at the farms examined

\begin{tabular}{lcccc}
\hline & & \multicolumn{2}{c}{$95 \%$ Confidence interval of the mean } \\
\cline { 3 - 5 } Sampling system & Farms, $\mathrm{n}$ & Mean $\%$ fat & Lower limit & Upper limit \\
\hline Portable & 1,337 & $3.7911^{\mathrm{a}}$ & 3.7779 & 3.8042 \\
Volumetric & 456 & $3.3702^{\mathrm{b}}$ & 3.3360 & 3.4043 \\
Electronic & 356 & $4.2237^{\mathrm{c}}$ & 4.1896 & 4.2578 \\
Total & 2,149 & 3.7734 & 3.7569 & 3.7899 \\
\hline
\end{tabular}

${ }^{a-c}$ Means within a column with different superscripts differ $(P<0.05)$

the significant variability in percentage of fat. Moreover, second-order interactions indicated that the effect of the sampling system on percentage of fat varied according to mean production. The full model explained $46.7 \%$ of the total variability observed in the percentage of fat data (Table 2).

The mean protein contents of the milk samples also varied according to the sampling system used (Table 3). Differences in milk protein concentrations were significant, although in terms of absolute values these differences were much lower than those observed in milk fat contents. In addition, significant differences in milk protein contents were detected between the portable, volumetric, and electronic sampling methods, but the volumetric and electronic methods failed to differ among each other.

The multivariate analysis revealed that the 3 factors examined (sampling device, mean milk production, and number of lactations completed in 2006) were able to explain a portion of the variation in percentage of protein values. Thus, the sampling device showed an effect that varied according to the number of lactations. The full model was only able to explain $19.2 \%$ of the variation in percentage of protein (Table 4).

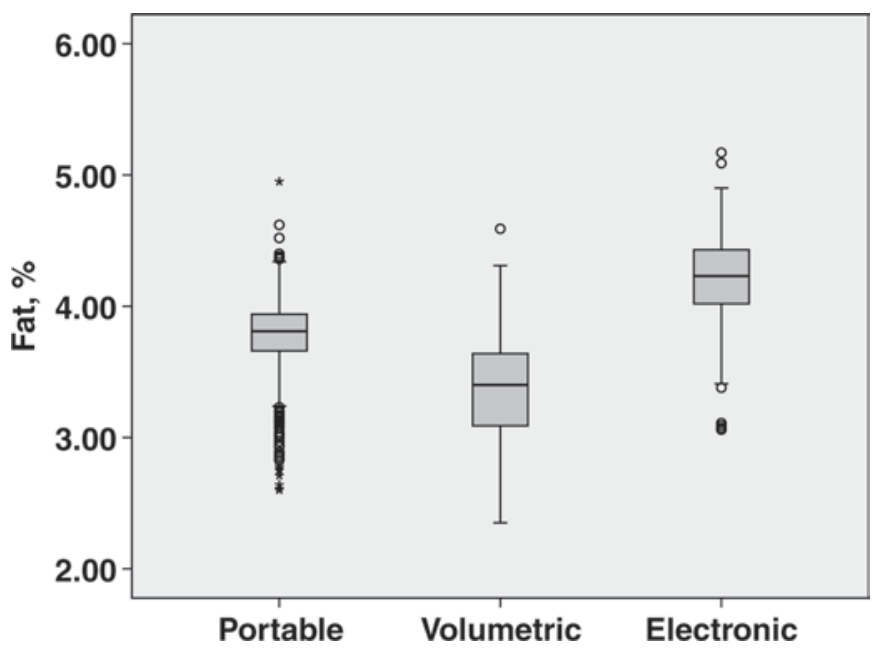

Figure 1. Box diagram of percentage of fat in milk by farm sampling system. Asterisks indicate extreme values of the distribution.

\section{DISCUSSION}

The findings of our study indicate significant differences in the percentage of milk fat values obtained using the different sampling devices. Similar differences were detected in terms of milk protein levels, but these results were less conclusive because of their lower statistical power.

Our data also revealed that percentage fat values varied with mean milk production. The interaction between the sampling system and milk production was also observed to affect the milk fat content. In general terms, the greater the mean production per cow was, the lower the fat content of milk measured. When the lactations examined were grouped according to the 4 mean milk production categories described previously, a $3.84 \%$ fat concentration was obtained for the lowest mean production quartile compared with $3.79 \%$ for the highest.

The type of milk meter used to obtain the milk samples was also able to explain some of the variations in milk protein levels but in smaller measure than for the fat levels. Milk protein variations were also partly explained by mean milk production and number of lac-

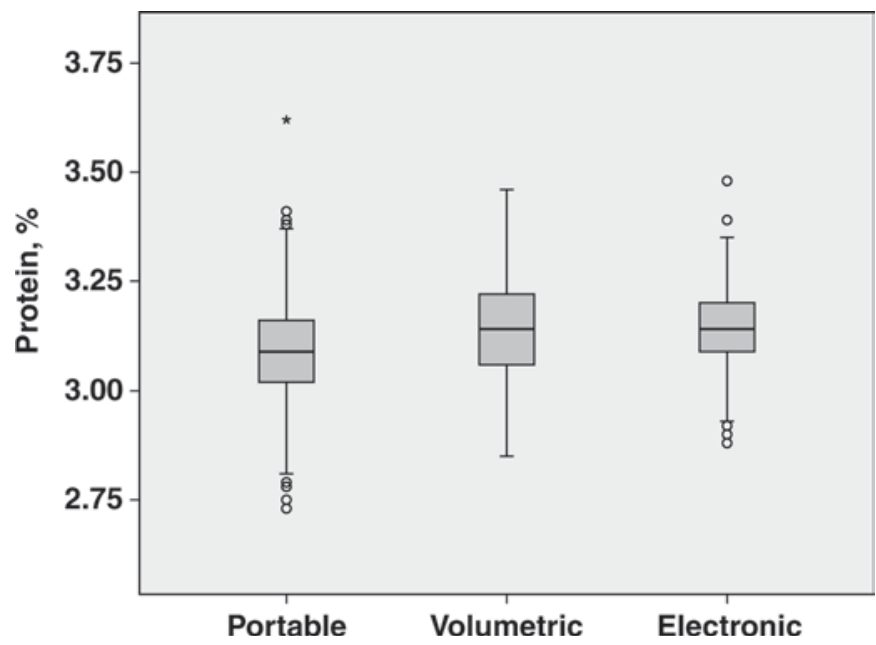

Figure 2. Box diagram of percentage of protein in milk by farm sampling system. Asterisks indicate extreme values of the distribution. 
Table 2. Analysis of variance of milk percentage fat according to the sampling system, milk production, and number of lactations

\begin{tabular}{lcr}
\hline Item & Sum of squares & df \\
\hline Total $^{*}$ & 92.158 & 8 \\
Sampling system (SS)* $^{*}$ & 77.093 & 2 \\
Milk production (P) $^{*}$ & 1.096 & 3 \\
No. of lactations (NL) $^{\text {Total* }}$ & 0.234 & 3 \\
$(\mathrm{SS} \times \mathrm{P})^{*}$ & 3.785 & 21 \\
$(\mathrm{SS} \times \mathrm{NL})$ & 2.345 & 6 \\
$(\mathrm{P} \times \mathrm{NL})$ & 0.442 & 6 \\
Model* & 0.862 & 9 \\
Residuals & 153.012 & 29 \\
Total & 174.708 & 2,119 \\
\hline
\end{tabular}

$* P<0.05$.

tations completed during 2006 at the individual farm level. Further, the sampling device used showed an effect that varied according to the number of lactations. In general, as for percentage of fat, it was observed that on the more modern, larger farms (greater number of lactations) in which electronic milk meters were frequent, feed rations often contained corn silage and higher contents of starch-rich materials that promote milk protein synthesis. Conversely, the smaller farms depended more on the intake of grass silage, reducing the animals' capacity for milk protein synthesis (Barbeito and López, 2007).

The results obtained suggest the overestimation of percentage of fat values obtained in milk samples from farms that used electronic sampling devices and underestimation when volumetric meters were used. Despite the bias that could be introduced when using a volumetric or electronic device to obtain milk samples, the idea of standardizing the milk sampling procedure used in farms subjected to official milk testing has not been put into practice for several reasons: 1) the cost of providing sampling systems for each milking point in large milking units, in which samples are obtained during electronic milk quantification; 2) the risk of destabilizing the milking vacuum by installing such devices in parlors with a vacuum reserve limited to the conventional features of the installation; and 3) the difficulty of finding an adequate installation site in parlors with low milk lines, given that the sampling device should be placed lower than at udder level and in a vertical position. When proportional meters are installed, effective vacuum level at the teat end could be affected, and consequently affect the milk flow speed but not the homogeneity and proportionality of the sample in field milking conditions.

Adequate mixing of the milk at the time of sampling is crucial to obtaining a representative sample, although this can cause considerable delays in milking (the sum of all the mixing times for each cow being milked). Any delay will also increase the risk of alteration of the fat globules in the milk and consequent lipolysis (Evers, 2004).

In studies comparing farms in which one of the factors considered is milk fat percentage, the type of sampling device used should be taken into account to avoid biases. Moreover, within a given herd, this confounding factor needs to be considered when interpreting both milk fat levels and the fat to protein ratio as an important indicator of nutrition state, nutrient conversion, and metabolism. The optimal fat-protein ratio is 1.2 to 1.4 (Cejna and Chladek, 2005); ratios above 1.4 indicating an energy deficiency and ketosis, whereas a ratio below 1.1 would raise a suspicion of rumen acidosis. If milk fat contents are over- or underestimated, this ratio will also be affected.

Yet another implication of our findings is that, because somatic cells bind to the fat fraction of the milk, the SCC will be affected if a homogenized sample is not obtained. An overestimated count would be expected in individual milk samples from cows for which the milking system used includes an electronic milk meter and an underestimated count expected in cows from milking parlors in which milk production is volumetrically determined (Read et al., 1986).

The genetic evaluation of an animal is also based on data from official milk testing. However, genetic assessments will not be affected by this bias in milk fat determination because the information used is corrected for any nongenetic influence (CONAFE, 2008). Thus, in the animal model used to calculate genetic value the effects of nongenetic factors on milk production such

Table 3. Percentage of protein values according to the sampling system used in the enrolled farms

\begin{tabular}{lcccc}
\hline & & \multicolumn{2}{c}{$95 \%$ Confidence interval of the mean } \\
\cline { 3 - 5 } Sampling system & Farms, $\mathrm{n}$ & Mean \% protein & Lower limit & Upper limit \\
\hline Portable & 1,337 & $3.0882^{\mathrm{a}}$ & 3.0826 & 3.0938 \\
Volumetric & 456 & $3.1415^{\mathrm{b}}$ & 3.1318 & 3.1513 \\
Electronic & 356 & $3.1406^{\mathrm{b}}$ & 3.1318 & 3.1494 \\
Total & 2,149 & 3.1082 & 3.1037 & 3.1126 \\
\hline
\end{tabular}

${ }^{\mathrm{a}, \mathrm{b}}$ Means within a column with different superscripts differ $(P<0.05)$. 
Table 4. Analysis of variance of percentage of protein according to the sampling system, milk production, and number of lactations

\begin{tabular}{lcr}
\hline Item & Sum of squares & df \\
\hline Total* & 2.250 & 8 \\
Sampling system (SS)* & 0.526 & 2 \\
Milk production (P)* & 0.607 & 3 \\
No. of lactations (NL)* & 0.182 & 3 \\
Total* & 0.366 & 21 \\
$(\mathrm{SS} \times \mathrm{P})$ & 0.081 & 6 \\
$(\mathrm{SS} \times \mathrm{NL})^{*}$ & 0.148 & 6 \\
$(\mathrm{P} \times \mathrm{NL})$ & 0.074 & 9 \\
Model* & 4.558 & 29 \\
Residuals & 19.179 & 2,119 \\
Total & 23.737 & 2,148 \\
\hline
\end{tabular}

$* P<0.05$.

as management are taken into account and within each herd, similarly managed cows are compared.

In summary, our findings indicate that the type of milk sampling system used has a substantial effect on the fat contents recorded in individual samples obtained for official milk testing. Such variation could arise from poor functioning of the equipment, inadequate mixing of the milk portion from which the sample is obtained, or from the nonproportionality of the sample. Samples obtained from only one point in the milk line may not be representative of all the milk produced. The most significant differences are observed in the percentage of fat and probably the SCC of the sample, whereas differences in percentage of protein are smaller. Finally, for a reliable analysis of the components of the milk sample, it should be ensured that the sampling method used provides a representative sample of the milk from a single milking. The sampling system should fulfill 2 basic requirements: to be proportional, meaning that a proportional sample of all the milking fractions should be collected; and to allow collection of a homogeneous sample, for which it is necessary to arrange an effective homogenization system. The gold standard would be the samples from portable meters, which are the only ones that always fulfill both conditions described.

\section{REFERENCES}

Barbeito, F., and C. López. 2007. Result of the management program from dairy cattle in Galicia 2006. Consellería do Medio Rural, Xunta de Galicia, Santiago de Compostela, Spain.

Bertrand, J. A. 1996. Influence of shipping container, preservative and breed on analysis of milk components of shipped samples. J. Dairy Sci. $79: 145-148$

Cejna, V., and G. Chladek. 2005. The importance of monitoring changes in milk fat to milk protein ratio in Holstein cows during lactation. J Cent. Eur. Agric. 6:539-546.

Coleman, D. A., and B. R. Moss. 1989. Effects of several factors on quantification of fat, protein and somatic cells in milk. J. Dairy Sci. 72:3295-3303.

CONAFE. 2008. Genetic Evaluation of Holstein Breed. Confederación Nacional de Frisona Española, Madrid, Spain.

Deeth, H. C., and C. H. Fitzgerald. 1978. Effect of mechanical agitation of raw milk on the milk fat globule in relation to the level of induced lipolysis. J. Dairy Res. 45:373-390.

Evers, J. M. 2004. The milk fat globule membrane-Compositional and structural changes post secretion by the mammary secretory cell. Int. Dairy J. 14:661-674.

International Committee for Animal Recording (ICAR). 2002. Recording Guidelines. http://www.icar.org/pages/recording_ guidelines.htm Accessed Sep. 30, 2002.

Ma, Y., and D. M. Barbano. 2000. Gravity separation of raw milk: Fat globule size distribution and fat content of milk fractions. J. Dairy Sci. 83:1719-1727.

Neitz, M.H. and Robertson, N.H. 1991. Composition of milk and factors that influence it. Directorate of Agricultural Information. Bulletin 421. USDA, Washington, DC.

Olson, C. C., and D. D. Amick. 1985. Weighing and sampling milk for DHI Test. Dairy Herd Improvement. National Cooperative Dairy Herd Improvement Program Handbook. http://www.agnr.umd. edu/DairyKnowledge/dairy/WEIGHING_AND_SAMPLING_ MILK_FOR_DHI_TESTS.html Accessed Sep. 22, 2002.

Quinn-Whelton, N., L. Killen, T. Guinee, and F. Buckley. 2007. Detection of abnormal recordings in Irish milk recorded data. Ir. J. Agric. Food Res. 46:117-127.

Read, R. B., J. G. Bradshaw, and A. R. Brazis. 1986. Influence of milk sample agitation on abnormal milk test scores. J. Dairy Sci. $52: 1682-1684$

Schutz, M. M., L. B. Hansen, and G. R. Steuernagel. 1990. Variation of milk, fat, protein and somatic cells for dairy cattle. J. Dairy Sci. 73:484-493.

Whittemore, C. T. 1980. Lactation of the Dairy Cow. Longman Handbooks in Agriculture. Longman Group, London, UK.

Wilmink, J. B. M., and W. Ouweltjes. 1992. Calculation of lactation production in the Netherlands. Pages 121-126 in Proc. of the 28th Biennial Session of the International Committee for Animal Recording (ICAR). Neustift im Stubaital, Tyrol, Austria. 